\title{
An attempt to calibrate the UHF strato-tropospheric radar at Arecibo using NexRad radar and disdrometer data
}

\author{
P. Kafando ${ }^{1,2}$ and M. Petitdidier ${ }^{1}$ \\ ${ }^{1}$ Centre d'Etudes des Environ. Terr. et Planétaire/Inst. Pierre Simon Laplace, 10-12 Av. de l'Europe, 78140 Vélizy, France \\ ${ }^{2}$ on leave to: Ouagadougou University, 04 B.P.8306 Ouagadougou 04, Burkina Faso
}

Received: 2 December 2003 - Revised: 18 June 2004 - Accepted: 20 July 2004 - Published: 22 December 2004

\begin{abstract}
The goal of this paper is to present a methodology to calibrate the reflectivity of the UHF Strato-Tropospheric (ST) radar located at NAIC in Puerto Rico. The UHF lower relevant altitude is at $5.9 \mathrm{~km}$, the melting layer being at around $4.8 \mathrm{~km}$. The data used for the calibration came from the observations of clouds, carried out with StratoTropospheric dual-wavelength (UHF and VHF) radars and a disdrometer; those instruments being located on the NAIC site in Arecibo, Puerto Rico. The National Weather Service operates other instruments like the radiosondes and the NexRad Radar in other sites.

The proposed method proceeds in two steps. The first consists of the comparison between the NexRad reflectivity and the reflectivity computed from the drop size distributions measured by the disdrometer for one day with a noticeable rainfall rate. In spite of the distance of both instruments, the agreement between the reflectivities of both instruments is enough good to be used as a reference for the UHF ST radar. The errors relative at each data set is found to be $2.75 \mathrm{~dB}$ for the disdrometer and $4 \mathrm{~dB}$ for the NexRad radar, following the approach of Hocking et al. (2001). The inadequacy between the two sampled volume is an important contribution in the errors.
\end{abstract}

The second step consists of the comparison between the NexRad radar reflectivity and the UHF non-calibrated reflectivity at the 4 altitudes of common observations during one event on 15 October 1998. Similar features are observed and a coefficient is deduced. An offset around $4.7 \mathrm{~dB}$ is observed and the correlation factor lies between 0.628 and 0.730 . According to the errors of the data sets, the precision on the calibration is of the order of $2 \mathrm{~dB}$. This method works only when there are precipitation hydrometeors above the NAIC site. However, the result of the calibration could be applied to other data obtained during the campaign, the only constraint being the same value of the transmitter power.

Correspondence to: M. Petitdidier

(monique.petitdidier@cetp.ipsl.fr)
Key words. Meteorology and atmospheric dynamics (tropical meteorology; remote sensing; instruments and techniques)

\section{Introduction}

Calibration of UHF/VHF wind profilers is essential to obtain absolute radar reflectivities and their variation as a function of time and meteorological conditions. Reflectivity is used to characterize the turbulence intensity through $\mathrm{C}_{n}^{2}$, the hydrometeors precipitating or non-precipitating. At VHF the contribution of the sky noise and its diurnal variation could be used to calibrate ST radars while at UHF the sky noise contribution is relatively small and is overwhelmed by the instrument noise (Campistron et al., 2001; Petitdidier et al., 1997). At UHF when the lowest reliable height is below the melting layer, precipitation parameters are compared with the ones measured with ground-based precipitation measurements like a disdrometer (Gage et al., 2000; William et al., 2000). In case of the UHF wind profiler at the National Astronomy and Ionospheric Center (NAIC) in Arecibo on the island of Puerto Rico, the lowest reliable height is above the melting layer, and then it is not possible to relate the hydrometeor characteristics to precipitation ones measured at ground level.

The purpose of this work is to present an attempt to calibrate indirectly the backscattered signal of a ST UHF radar. The data concerned by the calibration were taken at NAIC, in September/October 1998 during a campaign to observe tropical thunderstorms (Petitdidier et al., 2000). The observations of several clouds were carried out with the StratoTropospheric dual-wavelength (UHF and VHF) radars, an electric field mill, and a disdrometer, those instruments being located on the NAIC site. The National Weather Service has operated other instruments like the rain gauges, radiosondes and the Doppler weather radar, NexRad. Thus, the data collected will be used to describe tropical thunderstorms. 
The proposed calibration approach combines data from the disdrometer, the NexRad radar and the ST UHF radar. In the calibration of scanning weather radar, Gage et al. (2000) extended the disdrometer results to larger scales and to higher altitudes by means of a vertically directed UHF wind profiler. In our situation, the approach to calibrate the ST UHF radar must be different and the method consists of using the reflectivity computed from the drop-size distribution measurements by the disdrometer, to calibrate the reflectivity of the weather Doppler radar, NexRad, which, in turn, is used to calibrate the ST UHF reflectivity. Thus, it is vital that the initial relation, upon which this sequence of calibrations is based, be as accurate as possible.

This paper describes the calibration of the ST UHF radar by using the NexRad radar located in Cayey (Puerto Rico). In the first part of the paper, the simultaneous measurements are selected and the data obtained by the different instruments presented. The second part addresses the NexRad calibration. In order to avoid any assumption for the $\mathrm{Z}-\mathrm{R}$ relationship that it is highly variable during one event, reflectivities are compared. The third part concerns the UHF ST radar calibration. The comparison between the reflectivity observed by the UHF radar and the NexRad radar is carried out. As the attenuation of the UHF backscattered signal varies as a function of time, to avoid the receiver saturation the gain during the different periods has to be evaluated using the noise power spectral density. Then the backscattered signal is corrected by this factor and the comparison is done in the common range.

\section{Data}

2.1 Description (disdrometer, NexRad, UHF/VHF wind profilers)

During the whole campaign, outside the period of the hurricane Georges' passage, there were 18 days out of 29 when the disdrometer detected rain but only 7 days with a rain amount larger than $10 \mathrm{~mm}$. The Doppler weather radar, NexRad, data were available only for a few days ( 10 common periods with the ST radar observations out of 18) during the campaign. As a consequence, simultaneous measurements of disdrometer, ST UHF radar and NexRad Radar occurred only on 3 days, 18 and 30 September and 15 October, out of 7 noticeable rainfall events. Among these 3 days, on 30 September only the VHF radar was working, on 18 September the rainy period occurred before the ST UHF observations, so only on 15 October, we have simultaneous UHF and NexRad radar data.

\subsubsection{Disdrometer}

The data were collected with a Disdromet Joss-Waldvogel disdrometer (Joss and Waldvogel, 1967). One-minute samples of drop-size-distribution (DSD) were collected for 29 days from 15 September to 16 October, 1998. Rain was observed on 18 days, and the total number of DSDs equals 1298
Table 1. Geographical coordinates of the different instruments.

\begin{tabular}{llllll}
\hline & \multicolumn{2}{l}{ Latitude } & \multicolumn{2}{l}{ Longitude } & Altitude $(\mathrm{m})$ \\
\hline NexRad & $18^{\circ}$ & $6.94^{\prime} \mathrm{N}$ & $66^{\circ}$ & $4.68^{\prime} \mathrm{W}$ & 881.5 \\
Disdrometer & $18^{\circ}$ & $20.85^{\prime} \mathrm{N}$ & $66^{\circ}$ & $45.25^{\prime} \mathrm{W}$ & 364.24 \\
UHF Profiler & $18^{\circ}$ & $20.61^{\prime} \mathrm{N}$ & $66^{\circ}$ & $45.18^{\prime} \mathrm{W}$ & 230 \\
\hline
\end{tabular}

samples. Ulbrich et al. (1999) carried out a first analysis of the disdrometer data, obtained during the campaign.

The JWD records the number of raindrops, $\mathrm{nd}_{i}$, of diameter $\mathrm{D}_{i}$, in each of its 20 diameter channels, for a 1-min sampling period. The DSD, $\mathrm{N}\left(\mathrm{D}_{i}\right)$, expressed in $\mathrm{m}^{-3} \mathrm{~mm}^{-1}$, is computed from these counts $\mathrm{nd}_{i}$ by using:

$N\left(D_{i}\right)=\frac{n d_{i}}{S * d t * v\left(D_{i}\right) * d d_{i}}$,

where the measuring area, $\mathrm{S}$, is equal to $0.0050 \mathrm{~m}^{2}$; $\mathrm{dt}$ is the sampling period equal to $60 \mathrm{~s} ; \mathrm{D}_{i}$ is the mean diameter $(\mathrm{mm})$ for the ith channel, $\mathrm{dd}_{i}$ is the ith channel width $(\mathrm{mm}) ; \mathrm{v}\left(\mathrm{D}_{i}\right)$ is the fall speed in still air of a drop of diameter $\mathrm{D}_{i}$, expressed in $\mathrm{m} \mathrm{s}^{-1}$.

From the DSD, the rainfall rate and the radar reflectivity are deduced:

$R=6 \pi \times 10^{-4} \pi \int_{0}^{\infty} v(D) D^{3} N(D) d D$

where $R$ is expressed in $\mathrm{mm} / \mathrm{h} ; \mathrm{v}(\mathrm{D})$ in $\mathrm{m} / \mathrm{s}, \mathrm{D}$ and $\mathrm{dD}$ in $\mathrm{mm}$, and $\mathrm{N}(\mathrm{D})$ in $\mathrm{m}^{-3} \mathrm{~mm}^{-1}$.

$Z=\int_{0}^{\infty} D^{6} N(D) d D$

where $\mathrm{Z}$, the equivalent reflectivity, is expressed in $\mathrm{mm}^{6} \mathrm{~m}^{-3}$ with $\mathrm{N}(\mathrm{D})$ in $\mathrm{m}^{-3} \mathrm{~mm}^{-1}$ and $\mathrm{D}, \mathrm{dD}$ in $\mathrm{mm}$.

The drawback of the instrument occurs during strong rains. The impact of large drops causes such a strong internal noise response that the signal due to any small drop arriving during the ensuing few milliseconds - the dead time - is not detectable (e.g. Sauvageot et Lacaux, 1995). Applying the dead time correction proposed by the manufacturer has the effect of increasing the numbers of small drops, mainly where the many large drops are present, i.e. at high rain rates. The correction is not perfect, however, because, due to its multiplicative nature, it is not able to create drops in bins where none have been detected;

$n d_{j}^{*}=n d_{j} \exp \left\{\frac{0.035}{d t} \sum_{k=j-1}^{k=20} n d_{k} \ln \left[\frac{D_{k}}{0.85\left(D_{j}-0.25\right)}\right]\right\}$

Higher order moments of the raindrop size distribution such as rain rate and reflectivity, which are less dependent on the numbers of small drops - are going to be less affected than lower order moments, such as drop concentration, mean diameter (Uijlenhoet et al., 2002). 
Table 2. For an horizontal distance of $76 \mathrm{~km}$ from the NexRad radar, in the vertical direction above the NAIC site and as a function of the VCP11 elevation: H: Height of the central beam above NAIC, Z (MSL): altitude of the NexRad central beam above the NAIC site, taking into account the NexRad altitude, BW $(\mathrm{km})$ the vertical size of the beamwidth, DZ $(\mathrm{km})$ the distance between two consecutive central beams.

\begin{tabular}{lllllllllllllll}
\hline VCP11 & 0.4 & 1.45 & 2.40 & 3.35 & 4.30 & 5.25 & 6.2 & 7.5 & 8.7 & 10 & 12 & 14 & 16.7 & 19.5 \\
H km & 0.53 & 1.92 & 3.18 & 4.45 & 5.71 & 6.98 & 8.26 & 10.01 & 11.63 & 13.40 & 16.15 & 18.95 & 22.80 & 26.9 \\
Z km & 1.41 & 2.80 & 4.07 & 5.33 & 6.59 & 7.86 & 9.14 & 10.89 & 12.511 & 13.40 & 17.04 & 19.83 & 23.68 & 27.8 \\
BW km & 1.33 & 1.33 & 1.33 & 1.33 & 1.33 & 1.34 & 1.34 & 1.35 & 1.36 & 1.37 & 1.39 & 1.41 & 1.44 & 1.49 \\
DZ km & 0 & 1.39 & 1.26 & 1.26 & 1.26 & 1.27 & 1.27 & 1.75 & 1.62 & 1.77 & 2.75 & 2.79 & 3.85 & 4.11 \\
\hline
\end{tabular}

Table 3. Mean values of the distance and azimuth between the NexRad radar et and the other instruments, disdrometer and UHF radar.

\begin{tabular}{lll}
\hline & $\begin{array}{l}\text { Distance NexRad- } \\
\text { Instrument }\end{array}$ & Azimuth \\
\hline Disdrometer (15 October) & $76 \mathrm{~km}$ & $290^{\circ}$. \\
Radar UHF & $75.7 \mathrm{~km}$ & $289.7^{\circ}$ \\
\hline
\end{tabular}

\subsubsection{NexRad radar}

The Doppler weather radar, NexRad, is installed atop Cerro Baldios, around $8.15 \mathrm{~km}$ east of the city of Cayey, in the southwestern part of the island. Its geographical coordinates are in Table 1. The WSR-88D units are powerful $10 \mathrm{~cm}$-wavelength radars with approximately $1^{\circ}$ beamwidth by $250-\mathrm{m}$ range resolution, and a volume scan sampling period of 5 or $6 \mathrm{~min}$, according to the mode selected (Crum et al., 1993). According to the weather conditions, a specific scanning mode is selected. On 15 October, the precipitation mode selected was VCP11 that consists of volume scans at 14 elevations from $0.4^{\circ}$ to $19.5^{\circ}$ (Table 2). The scanning time period is $5 \mathrm{~min}$ with a pulse length of $1.57 \mu \mathrm{s}$. The discrete values of the elevations provide a relatively poor vertical resolution from $1.26 \mathrm{~km}$ to $1.76 \mathrm{~km}$ for the elevation lower than $12^{\circ}$; for upper elevations the vertical resolution goes from 2.8 to $4 \mathrm{~km}$ (Table 2). Above an elevation of $6.2^{\circ}$ there are altitude gaps between the different beams. The beamwidth varies from $1.33 \mathrm{~km}$ for elevations of $0.4^{\circ}$ to $4.3^{\circ}$, to $1.49 \mathrm{~km}$ for an elevation of $19.5^{\circ}$.

The radar reflectivity factor $\mathrm{Z}\left(\mathrm{mm}^{6} \mathrm{~m}^{-3}\right)$ is related to the size distribution of the raindrops in the radar sample volume according to:

$Z=\int_{0}^{\infty} D^{6} N(D) d D$.

\subsubsection{UHF ST radar}

During this experiment the measurements were carried out simultaneously at UHF $(430 \mathrm{MHz})$ and VHF $(46.8 \mathrm{MHz})$ with a $2-\mu$ s pulse, the inter-pulse period (IPP) being $1 \mathrm{~ms}$. The first 50 gates are consecutive and their sampling starts at $40 \mu \mathrm{s}$; the last ten gates correspond to internal calibration the sampling of this group starting at $900 \mu \mathrm{s}$. The in-phase and in-quadrature data are recorded without any coherent integration. The UHF radar operated in the near field. The three-decibel beam radius was $0.085^{\circ}$. The beam may be considered as a $300 \mathrm{~m}$-diameter cylinder (Farley, 1983).

The relationship to compute the mean height of the first sample or gate takes into account the zenith angle, and various delays (Cho, private communication, 1994). In UHF, the lowest reliable gate was at $5.9 \mathrm{~km}$, an altitude that does not allow observation of the melting level, which, in the tropics, is typically around $4-4.5 \mathrm{~km}$. During the observations, in order not to saturate the receiver, different attenuations were included. The variation, as a function of time, of the noise power spectral density points out such attenuation changes.

\subsection{Location of the instruments, distance and azimuth rela- tive to the NexRad radar}

First, from the latitude and longitude of each instrument (see Table 1), using different geoids we calculate the distance and the azimuth of the disdrometer relatively to the NexRad radar. The difference among the estimates was very small. Table 3 provides the values of the final distances and azimuths.

Table 2 gives the height above the NexRad radar and the altitude (MSL) of the central beam at $76 \mathrm{~km}$, location of the disdrometer and the UHF ST radar, as a function of the NexRad elevation angle. The NexRad beamwidth in the vertical direction, expressed in $\mathrm{km}$, is also given in Table 2.

The main drawback of this calibration is the distance between both instruments.

\section{Meteorological situation}

Only on 15 October UHF measurements were observed at the same time when the thunderstorm occurred. Figure 1 presents the variation of the NexRad reflectivity for an elevation of $0.4^{\circ}$ at different times. We observed the different phases of the cloud activity, located in the northwest quadrant of the island with the NexRad radar being located in the southwestern part. At 18:30 UT the cloud was at the limit of the NAIC site, noted by a star. Then it expands and the NAIC site is inside the cloud formation. At 20:43 UT its 

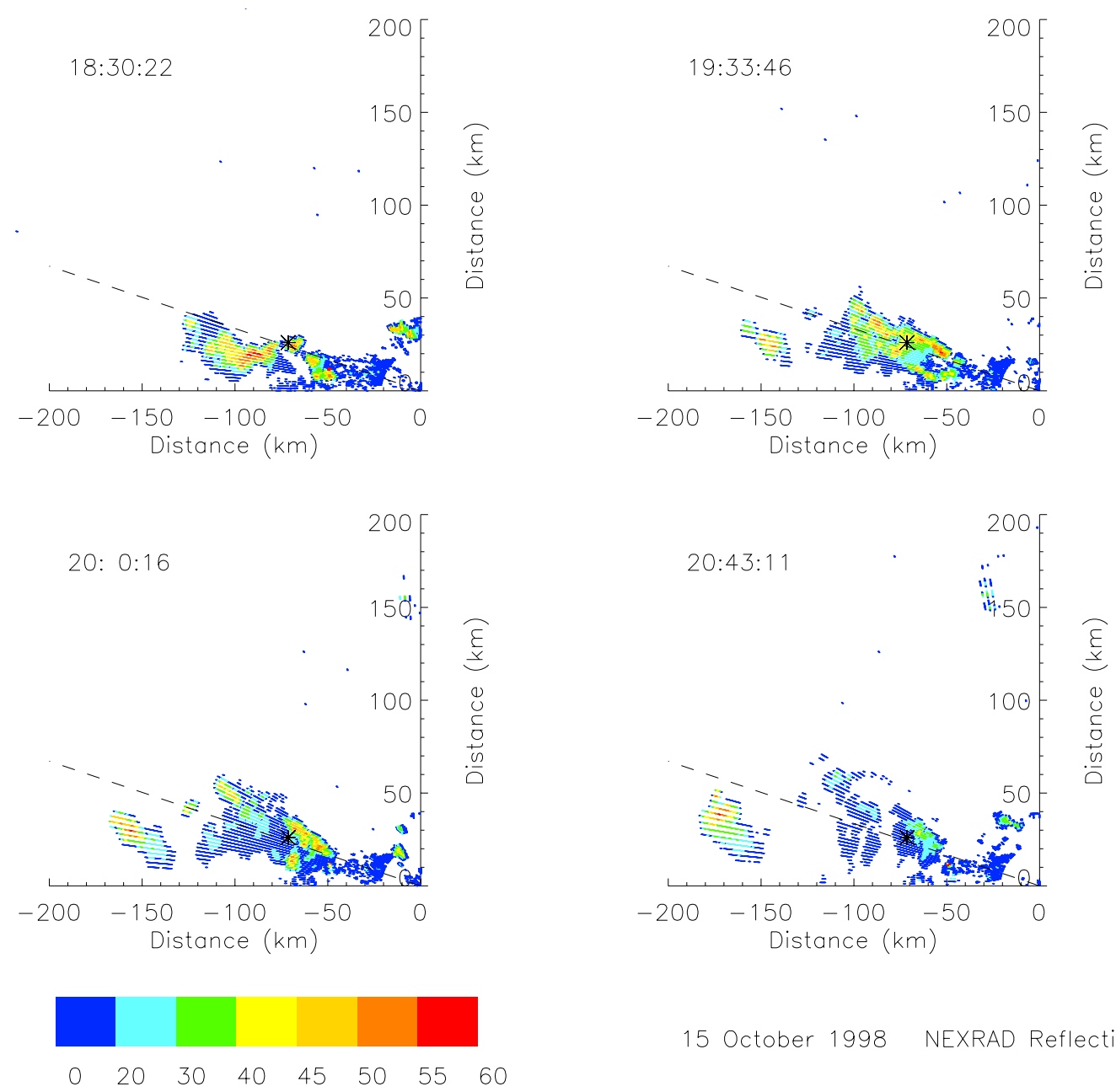

15 October 1998 NEXRAD Reflectivity

Fig. 1. Horizontal display of the NexRad reflectivity (dBZ) in color scale at an elevation of $0.4^{\circ}$ observed in the northwest quadrant at different lifetimes of the clouds.

decay is observed. The high reflectivity spots are relatively small, then they may be close to the NAIC site but not above.

Figure 2 presents the variation of the rainfall rate, R, the mass weighted mean diameter, $D_{m}$, and the reflectivity, $Z$. There is a period of intense convective activity with rainfall rate attaining $150 \mathrm{~mm} / \mathrm{hr}$. The shape of the cloud formation and its time evolution as seen by NexRad explains the time variation of the rainfall rate and reflectivity retrieved from the disdrometer data with the high reflectivity spot moving close by the NAIC site. After 19:35 until 20:15 the continuous decrease of $R, Z$ and $D_{m}$ is characteristic of a stratiform stage. Then the reflectivity, rain fall rate and mean diameter increase. At 21:00 it is the end of the precipitation that corresponds to the cloud activity decay observed at 20:43.

Figure 3 presents the variation of the UHF reflectivity expressed in relative $\mathrm{dB}$, and the hydrometeor velocity observed in the vertical beam. The wind field above the melting layer is dominated by upward motion. An alternation of upward and downward motions is observed between 10 and $12 \mathrm{~km}$ with a period approximately $15 \mathrm{~min}$. After 20:45 UT the reflectivity decreases above $9 \mathrm{~km}$ related to the decay of the cloudy activity. The reflectivity presents large variation due to the change of attenuation that was applied in order not to saturate the receiver. It is difficult to relate the UHF observations to the condition at the ground level. Due to wind shears the flanks of the "tower" are bent and then the top is not actually at the vertical of the base. The ST radars provide a cut of the cloud part passing over them.

The meteorological situation is complex due to the different stages of the cloud, convective and stratiform activity. The types of precipitation and hydrometeor are different from the convective stage to the stratiform one and during the decay.

\section{NexRad calibration}

\subsection{Comparison with the disdrometer}

The first step is to compare the NexRad reflectivity with the reflectivity deduced from disdrometer data. Ulbrich and Lee (1999) found a case of a systematic offset in NexRad 


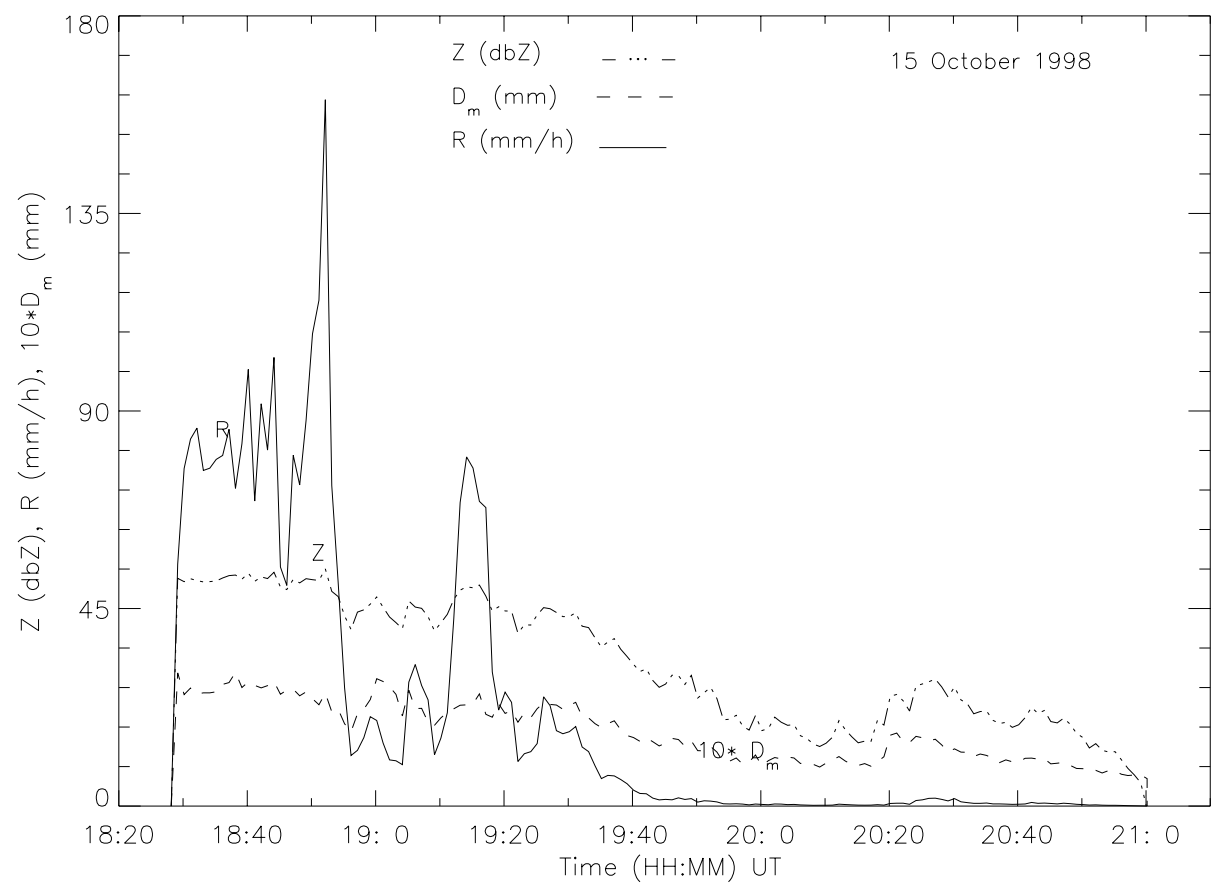

Fig. 2. Time evolution of rainfall rate, $\mathrm{R}$, and mass weighted mean diameter, $\mathrm{D}_{m}$, and reflectivity, on 15 October 1998 between $18: 20$ and 21:00 UT.

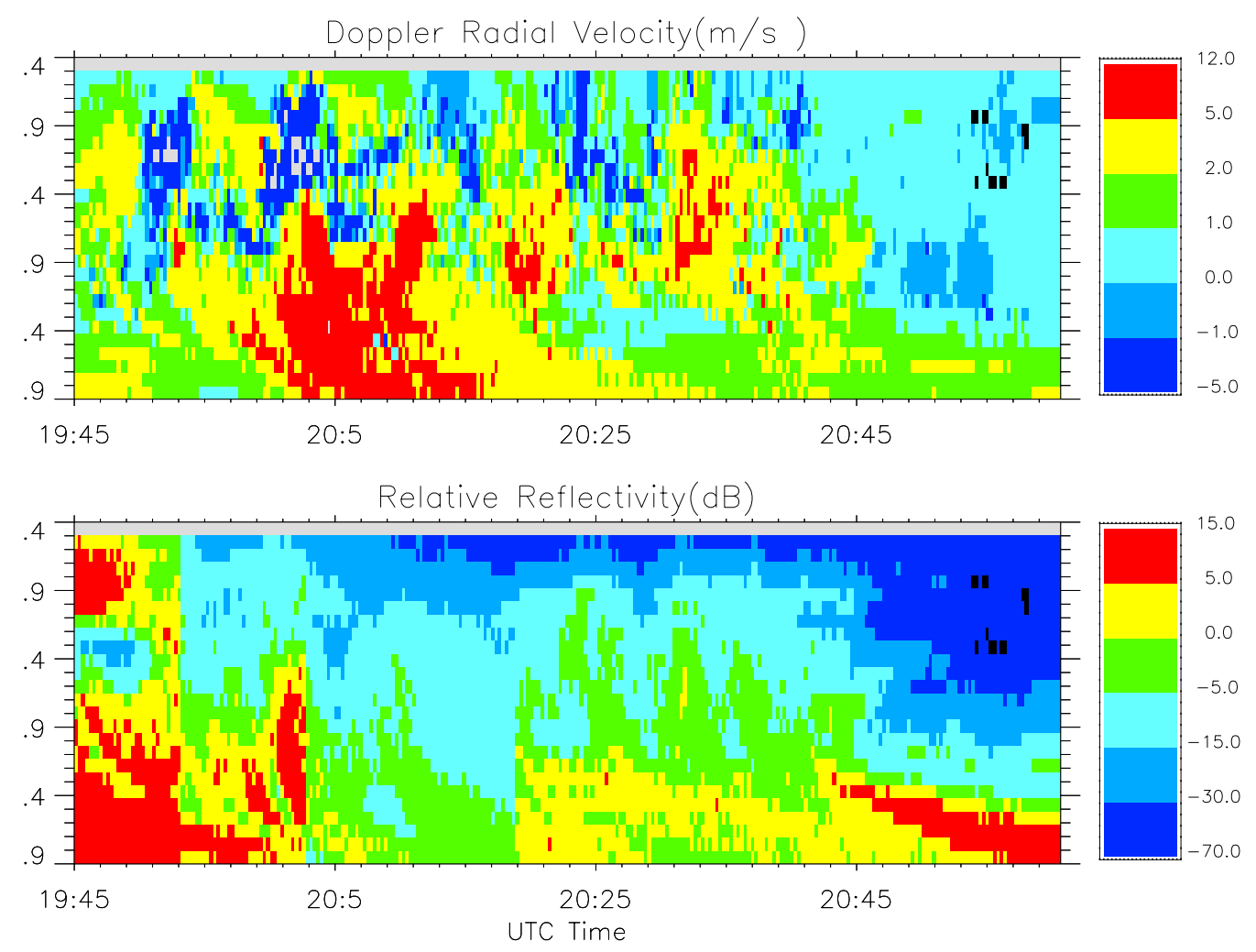

Fig. 3. UHF Strato-tropospheric radar: the lower plot represents the relative reflectivity in color scale (relative dB) as a function of altitude and time; the upper plot represents the Doppler velocity in the vertical beam in color scale $(\mathrm{m} / \mathrm{s})$ as a function of altitude and time; positive values correspond to upward motion. 


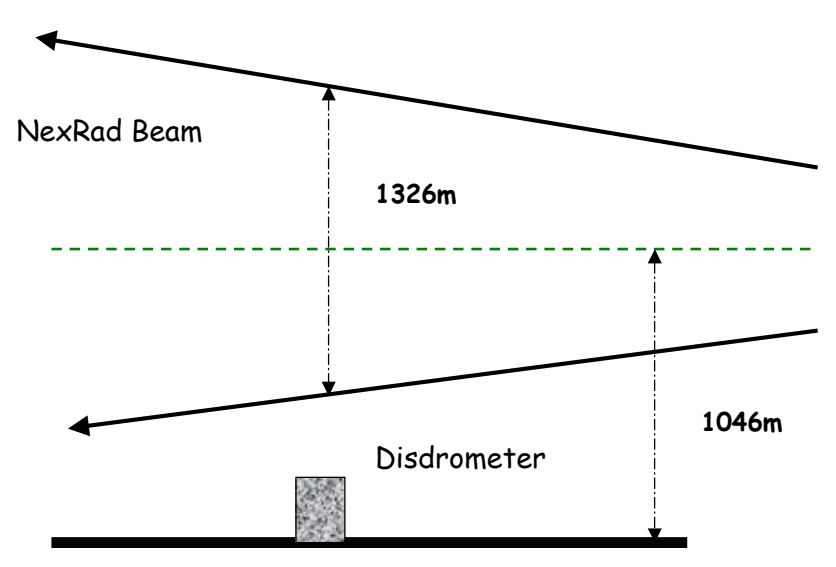

Fig. 4. Sketch to represent relative locations of the disdrometer and the NexRad radar beam.
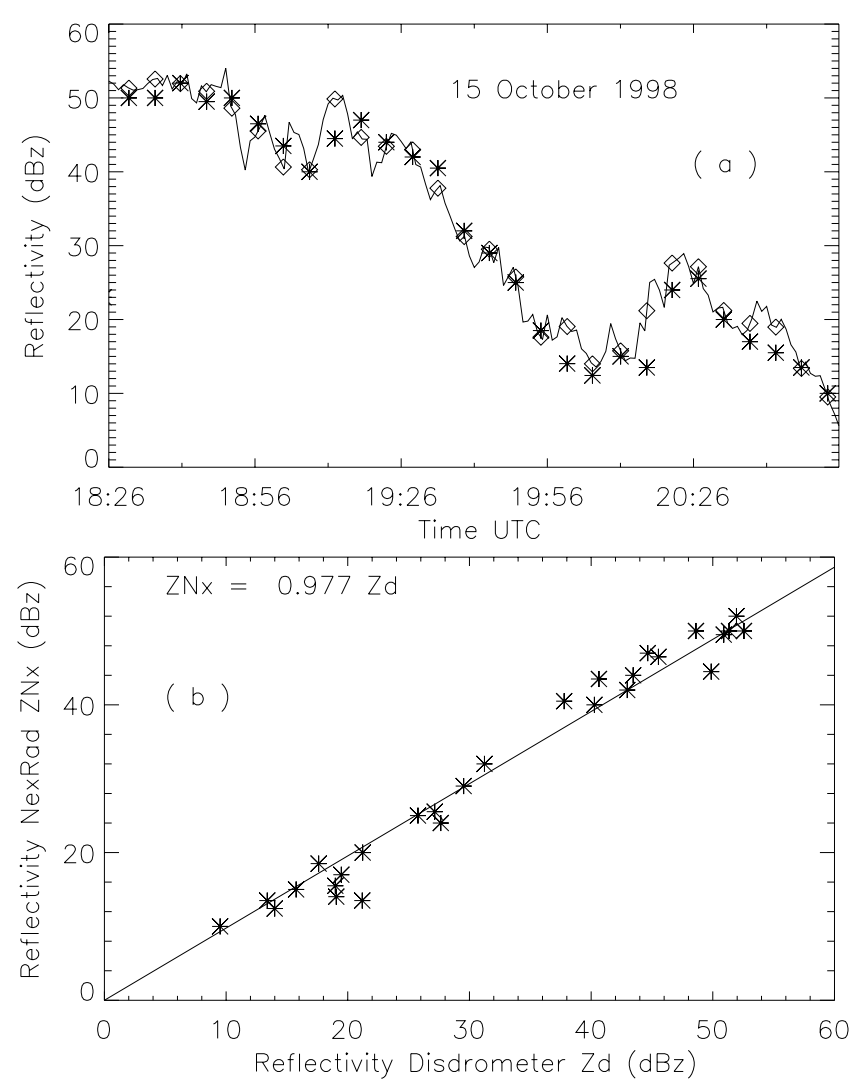

Fig. 5. (a) Time variation of the disdrometer and NexRad radar reflectivities on 15 October 1998: Solid line and diamond: reflectivity computed by using drop size distribution measured by the disdrometer. Star: Reflectivity measured by the NexRad radar. (b) NexRad reflectivity as a function of the disdrometer reflectivity.

radar constant around $-5.4 \mathrm{~dB}$ and noticed that it occurs with other NexRad radars. Previous encouraging tests were carried out by comparing the rainfall rate retrieved from this NexRad radar in Puerto Rico with the measurements of the rain gauge network (Briceño, 2002). For this comparison a relation between the radar reflectivity factor and the rainfall rate is assumed and is dependent on the type of rain. Then a comparison of the radar reflectivity with reflectivity computed from disdrometer data avoids that assumption.

Figure 4 provides a schema of the position and width of the NexRad beam just above the disdrometer; the radar beamwidth covers about $1.33 \mathrm{~km}$ in altitude. The selected NexRad data are chosen at the lowest elevation $0.4^{\circ}$. Since the radar sampling (elevation, and azimuth) may vary from scan to scan, in order to avoid interpolation, the NexRad data located above the disdrometer are searched in the following azimuth area, $290^{\circ} \pm 0.5^{\circ}$ and range distance area $76 \mathrm{~km} \pm 0.3 \mathrm{~km}$.

From Eq. (3), the reflectivity is deduced for 15 October. Figure 5a presents the time variation of the disdrometer reflectivity, $Z d$, superimposed and the values of the NexRad reflectivity, $Z n x$, are indicated by a star.

The NexRad beamwidth intercepts a range of $1.33 \mathrm{~km}$ around a mean altitude of $1.4 \mathrm{~km}$ MSL or $1.046 \mathrm{~m}$ above the disdrometer site. Due to the height difference between the disdrometer and the central beam axis above the disdrometer, i.e. $1046 \mathrm{~m}$, the time delay between the precipitation located in the NexRad beam and the observed one, by the disdrometer, is fixed from 2 to $3 \mathrm{~min}$, according to the mean drop size. Gage et al. (2000) found a difference of about $2 \mathrm{~min}$ between the UHF reflectivity at $327 \mathrm{~m}$ and the disdrometer one. The time delay cannot be precise, as the precipitation is not distributed homogenously vertically inside the beam, and the beamwidth and the central beam distance to the disdrometer are very large. On 15 October, no significant difference is pointed out between the computed reflectivity and the observed one, by the radar, in the event observed. No systematic offset is observed like Ulbrich and Lee (1999) did.

The coefficients of the relation, $Z n x$ as a function of $Z d$, can be obtained by applying a linear regression to the $(Z d$, $Z n x)$ points, $Z d$ being the disdrometer reflectivity and $Z n x$ the NexRad reflectivity. In particular, we apply a robust, least absolute deviation method (Press et al., 1986), which minimizes the mean absolute deviation, i.e.,

$M=\sum_{1}^{n}|Z n x-a-b Z d|$.

In our case we obtain:

$Z n x=0.977 Z d$.

With $\mathrm{M}$, the mean absolute deviation for each data-point in the $Z n x$ direction, is equal to $1.63 \mathrm{~dB}$.

In order to take into account the uncertainties in the disdrometer and NexRad measurements, we follow the approach given by Hocking et al. (2001). Then from this method we determine a relation between $\mathrm{g}_{o}$, the correlation factor between $Z n x$ and $Z d$, and the $\sigma_{Z d}$ and $\sigma_{Z n x}$ variables that reflect not only the intrinsic measurements errors of each instrument, but also contain information about the difference between the two techniques. In this case we obtain:

$0.977 \leq g_{o} \leq 1.05$, 

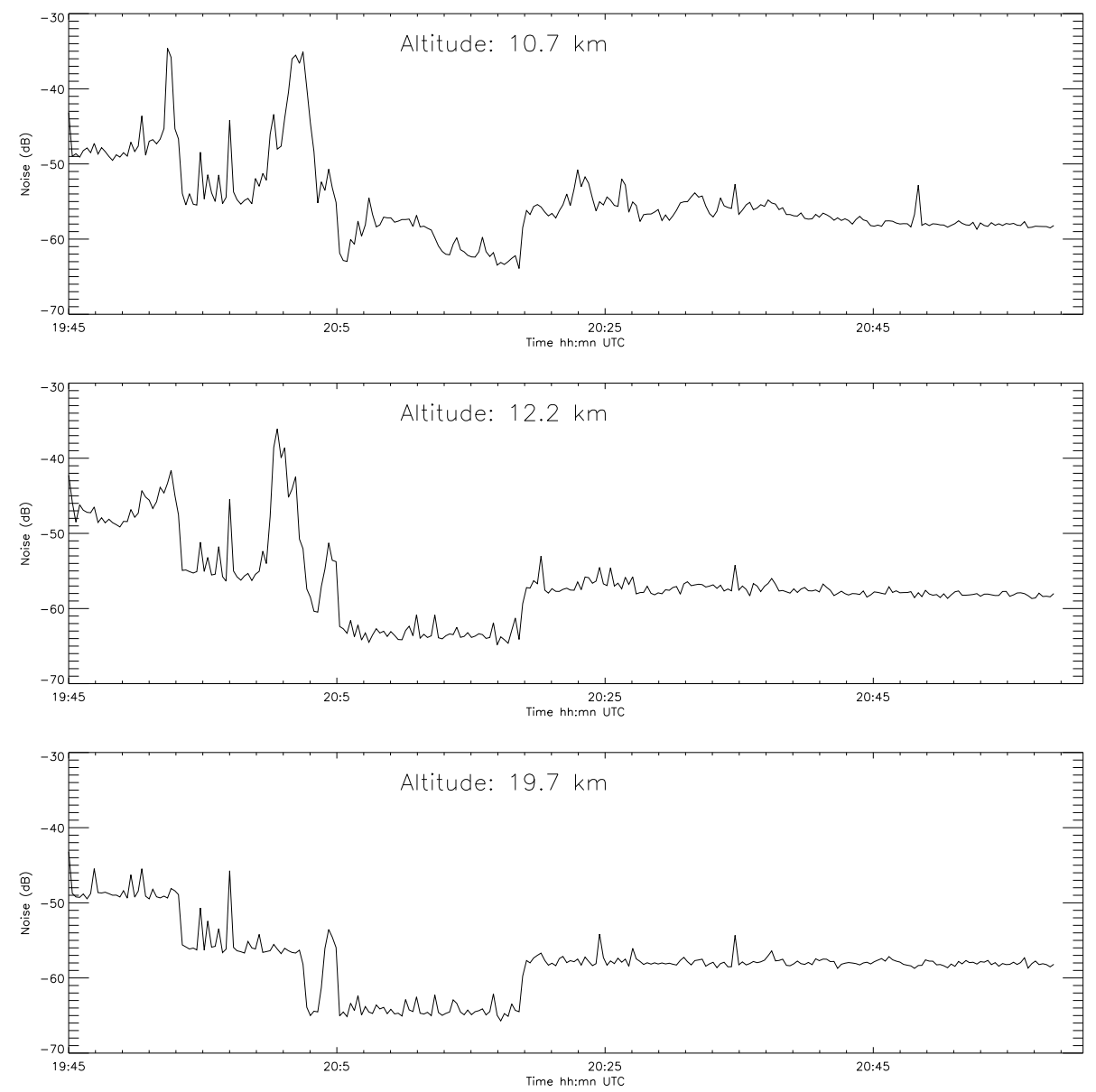

Fig. 6. Variation of the UHF noise power spectral density as a function of time at different altitudes, from top to bottom, $10.7 \mathrm{~km}, 12.2 \mathrm{~km}$ and $19.7 \mathrm{~km}$.

with $0 \mathrm{~dB} \leq \sigma_{Z d} \leq 4.5 \mathrm{~dB}$

and $4.9 \mathrm{~dB} \geq \sigma_{Z n x} \geq 1.8 \mathrm{~dB}$

where $4.9 \mathrm{~dB}$, the error for the NexRad is obtained when it is assumed that there is no error on the disdrometer data; 1.8 corresponds to an error of $4.5 \mathrm{~dB}$ on the disdrometer data. If we assume that $\mathrm{g}_{o}$ is equal to 1 , then $\sigma_{Z d}$ and $\sigma_{Z n x}$ are equal to $2.75 \mathrm{~dB}$ and $4 \mathrm{~dB}$, respectively. A large part of the errors is due to the difference in volume sampling and location.

\subsection{Conclusion}

The equivalent reflectivity computed from the disdrometer drop sizes was considered as a reference for the NexRad reflectivity. From the results obtained while comparing the NexRad reflectivity and the one deduced from the disdrometer data, we can consider that the calibration of the NexRad radar is quite good, taking into account all the assumptions due to the meteorological conditions and the setting of both instruments.

\section{UHF ST radar calibration}

\subsection{Attenuation}

The noise power spectral density was computed by using the "segment" method (Petitdidier et al., 1997). It consists of dividing the spectrum into equal-length segments and using the average power from those two segments that have the lowest average. The number of points in each segment is 16 with a 256-point FFT. This method is faster than the method, proposed by Hildebrandt and Sekhon (1974), and the underestimation bias between the two methods is small if the number of points averaged is large. Instead of averaging a large number, $\mathrm{N}$, of consecutive values, with the risk of including atmospheric or clutter signal, it is better to average 2 values, each of them an average of N/2 points.

In order not to saturate the receiver, different attenuations are introduced during the experiment. Their values may be written into the log but not into the header. Figure 6 presents the variation of the noise spectral density at different altitudes. At the higher altitude of $19.7 \mathrm{~km}$ the change in attenuation is clearly observed; these values were taken into 

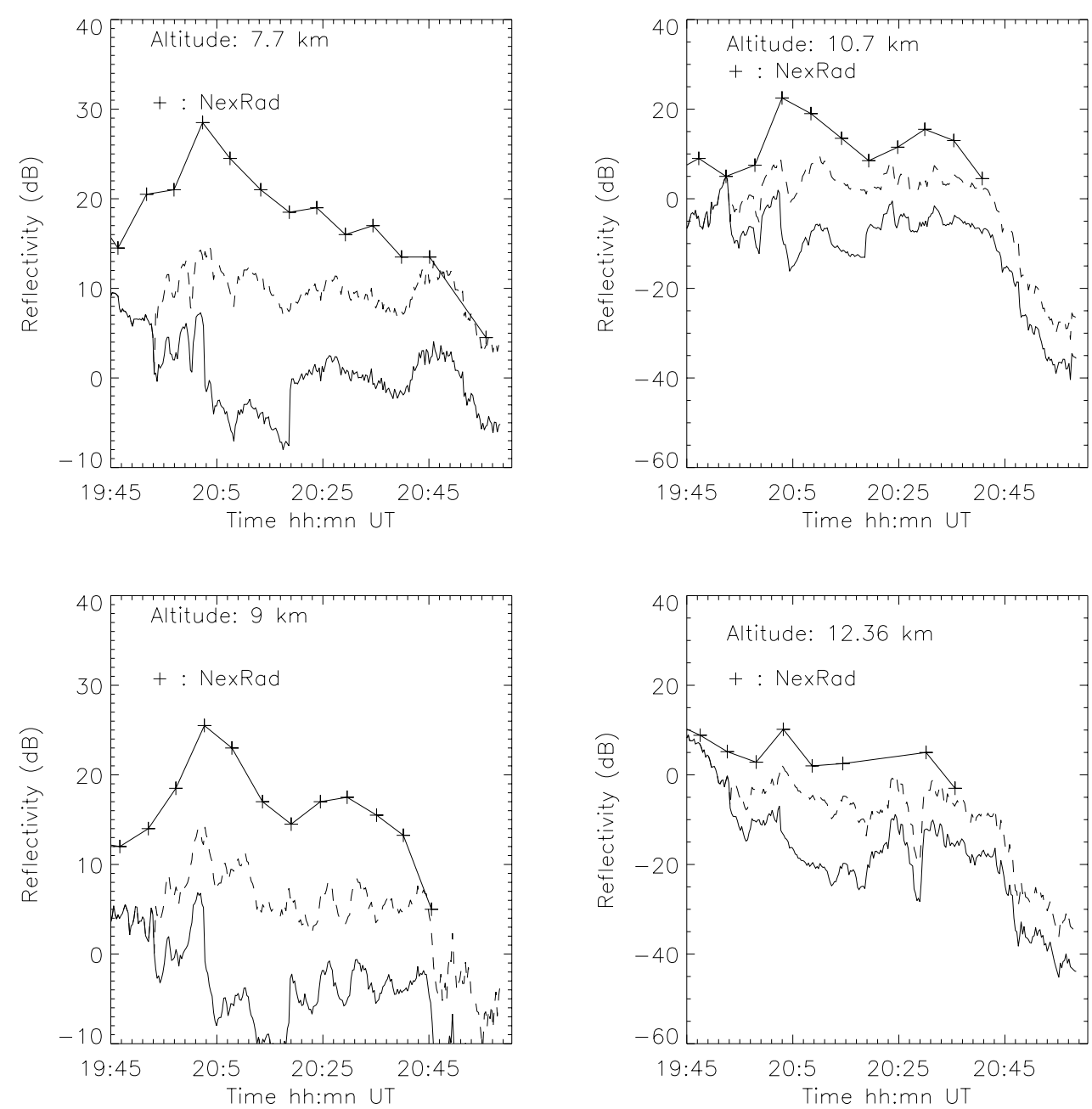

Fig. 7. Time evolution of the reflectivity of UHF and NexRad radars at different altitudes on 15 October 1998. The UHF radar reflectivity is averaged over 5 gates, i.e. $1.500 \mathrm{~km}$, in order to be compared to the NexRad data whose beamwidth is $1.3 \mathrm{~km}$.

account to correct the reflectivity. Some spikes are observed. The larger one is due to a helicopter that transports material and flew several times close to the NAIC site, while the other spikes point out the presence of lightning radiation. At lower altitudes, the non-stationarity of the noise may be due to intense echo leakage over the frequency range.

5.2 Comparison between NexRad and wind profiler reflectivities

The UHF beam is quite a $300 \mathrm{~m}$-diameter cylinder as the radar works in near field (Farley, 1983). The intersection of the NexRad with the UHF beam is the intersection of a vertical cylinder (UHF beam) and a portion of a cone with its central axis at different elevations, $5.25^{\circ}, 6.2^{\circ}, 7.5^{\circ}$ and $8.7^{\circ}$. Table 2 provides the altitude (MSL) of the central beam and Table 1 gives the altitude of the UHF ST radar, i.e. $0.230 \mathrm{~km}$. For a given elevation at the NAIC site the altitude range covered by the NexRad beam is $1.35 \mathrm{~km}$, corresponding to 4.5 gates of the UHF ST radar; tests have be done with 4 and 5 gates. Between the average over 3, 4 or 5 gates the mean values of the UHF reflectivities obtained are very close toeach other. The NexRad pulse length fills approximately the UHF beam but the uncertainty is the central point of the NexRad sampling, i.e. the portion of the pulse inside the UHF ST beam.

Figure 7 presents a comparison of the NexRad and UHF corrected and uncorrected reflectivities. Some similar features are observed. The differences are due to the relatively small size of the cloud and the fact that from one scan to the other the NexRad radar did not observed exactly the same zone. At $12.36 \mathrm{~km}$ the number of common observation points is scarce because it is the upper limit of the cloud.

Figure 8 presents the variation of the UHF relative reflectivity as a function of the NexRad reflectivity. Looking for the relation between the UHF ST radar and the NexRad radar reflectivities we apply the same robust, least absolute deviation method as in Sect. 4.1, we obtain:

$Z_{\mathrm{UHF}}=0.628 Z n x-4.33$, 
with $\mathrm{M}$, the mean absolute deviation for each data-point in the $\mathrm{Z}_{U H} \mathrm{~F}$ direction, equal to $2.13 \mathrm{~dB}$.

Now we follow the approach given by Hocking et al. (2001), then we obtain a relation between the correlation factor $\mathrm{g}_{o}$, and the errors related to each set of data.

$0.628 \leq g_{o} \leq 0.730$

with $0 \mathrm{~dB} \leq \sigma_{Z n x} \leq 2.75 \mathrm{~dB}$

and $2.06 \mathrm{~dB} \geq \sigma_{\mathrm{Zuhf}} \geq 0.88 \mathrm{~dB}$.

In comparison with the values obtained with the disdrometer and the NexRad radar, the errors are smaller. That may be due to a better adequacy between the UHF ST radar and NexRad radar measurements. If we assume the errors equal for both sets of data, the value of $\mathrm{g}_{o}$ is equal to 0.664 and the error for each data set is around $1.73 \mathrm{~dB}$. The offset, $-4.33 \mathrm{~dB}$, is $0.01 \mathrm{~dB}$ higher than in Eq. (10).

If we take the maximum value of $\mathrm{g}_{o}$, i.e. 0.730 , the offset is equal to $-5.17 \mathrm{~dB}$, i.e. $0.76 \mathrm{~dB}$ lower than in Eq. (10). The errors on the NexRad and the UHF ST radar data are equal to $2.75 \mathrm{~dB}$ and $0.88 \mathrm{~dB}$, respectively. On Fig. 8 these two extreme values proposed for $\mathrm{g}_{o}$ are also plotted .

In conclusion, in the range of values of $\mathrm{g}_{o}$ the error on the calibration of the UHF ST radar is of the order of $2 \mathrm{~dB}$, similar to the maximum error on the UHF data.

\section{Conclusion}

A methodology has been developed to calibrate the UHF ST radar at NAIC whose lowest observing altitude is above the melting layer because classical calibration based on the observed precipitation cannot be used. The methodology consists of combining disdrometer and NexRad radar reflectivities and then of combining the NexRad and UHF ST radar reflectivities.

The work first investigated the quality of the calibration of the Doppler weather radar, NexRad, located $76 \mathrm{~km}$ apart from the NAIC site. The radar reflectivities were compared with the reflectivities retrieved from the disdrometer data obtained at NAIC. In the case studied, we observe a fairly good agreement between both sets of data. There is no systematic offset or it is very small. Using the approach of Hocking et al. (2001) we found a range of values for the correlation factor, $\mathrm{g}_{o}$, going from 0.977 to 1.05 . However, assuming a coefficient $\mathrm{g}_{o}$ equal to 1 , the errors related of each set are $2.75 \mathrm{~dB}$ and $4 \mathrm{~dB}$ for the disdrometer and the NexRad radar, respectively. These values may rather reflect the difference in volume sampling and location. In conclusion, the calibration of the NexRad radar is good enough to be used as a reference for the UHF ST radar.

The final step concerned the calibration of the UHF ST radar. At first, we take into account the variation of the signal attenuation determined by the noise power spectral density and then correct the signal from this effect. The reflectivity of the UHF ST radar was compared with the NexRad

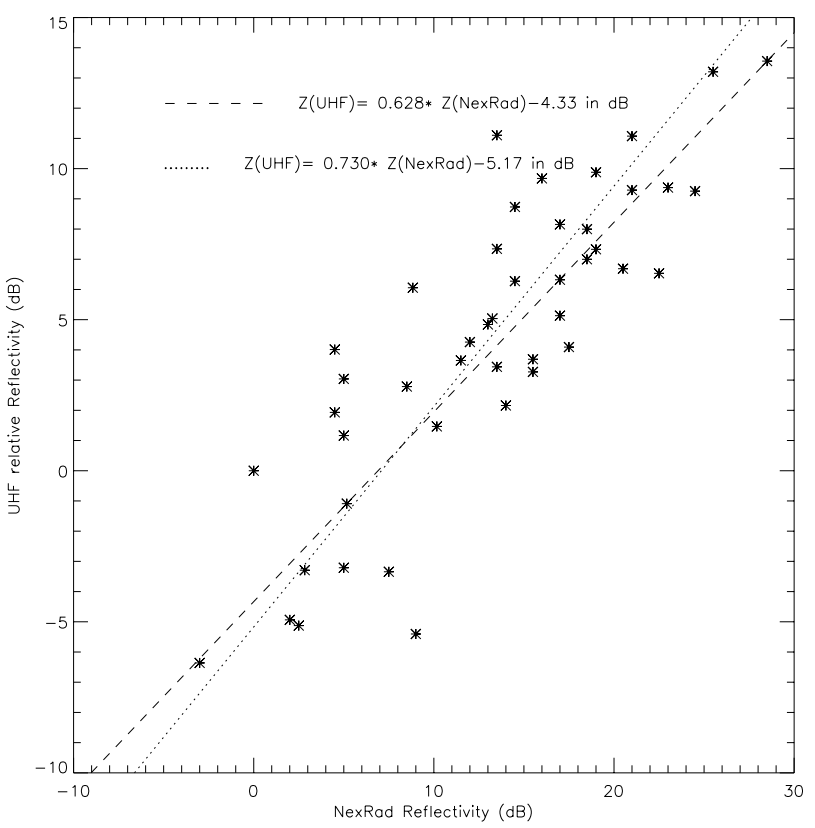

Fig. 8. UHF corrected reflectivities as a function of the NexRad reflectivities for all 4 altitudes of Fig. 7. The two lines represent the extreme values of the slope, $\mathrm{g}_{o}$, assuming different values of the errors, $\sigma$, on each data set, following the approach of Hocking et al. (2001).

reflectivity at the 4 altitudes of common observations. We obtain a relation between both radar reflectivities. The offset is about $4.7 \mathrm{~dB}$ and the correlation factor varies between 0.628 to 0.730 . The precision of the calibration is of the order of $2 \mathrm{~dB}$ related to the errors of comparing these two different techniques. UHF ST radar reflectivity, observed on 15 October 1998, is calibrated. Several issues arise from this result. The calibration is only possible when hydrometeors are present. Then the result of the calibration can be used for other events, assuming that the transmitter power of the radar is fixed at the value of the calibration event. As a matter of fact, the noise power spectral density will be compared to the one used as a reference during the calibration event; the UHF reflectivity is corrected and calibrated with the relation obtained during the calibration event.

Acknowledgements. The National Astronomy and Ionospheric Center in Arecibo is operated by Cornell University under contract with the National Science foundation. The authors would like to thank C. Ulbrich (Clemson University, USA), P. Laroche (ONERA, France), E. Campos (McGill University, Canada) for their participation to the project and/or to the field campaign. The authors were very grateful to the NAIC staff for their efforts to keep our experiment running after the large damage created by the passage of Hurricane Georges; and also all along the campaign to P. Perillat who provided his technical assistance and C. Tepley. his scientific support and encouragements.

The participation to the field experiment of M. Petitdidier was sponsored by a travel grant from CNRS "Programme National Chimie Atmosphérique". This work was undertaken while P. Kafando was at Centre d'études des Environnements Terrestre et Planétaires, 
France, with a fellowship from "Agence Universitaire de la Francophonie".

Topical Editor U.-P. Hoppe thanks two referees for their help in evaluating this paper.

\section{References}

Briceño Murillo, J. A.: Comparison of rain estimates using TRMN, NexRad and rain gauges over Puerto Rico, Master of Science in Computer Engineering, University of Puerto Rico, Mayagüez PR, 2002.

Campistron, B., Despaux, G., Lothon, M., Klaus, V., Pointin, Y., and Mauprivez, M.: A partial $45 \mathrm{MHz}$ sky temperature map obtained from the observations of five ST radars, Ann. Geophys., 19, 863-871, 2001.

Crum, T. D., Alberty, R. L., and Burgess, D. W.: Recording, archiving, and using WSR-88D data, Bull. Amer. Meteor. Soc., 74, 645-653, 1993.

Farley, D. T.: Antenna size for MST radars, Handbook for MAP, Vol. 9, 465-466, 1983.

Gage, K. S., Williams, C. R., Johnston, P. E., Ecklund, W. L., Cifelli, R., Tokay, A., and Carter, D. A.: Doppler Radar profilers and calibration tools for scanning radars, J. Appl. Meteor., 39, 2209-2222, 2000.

Hildebrandt, P. H. and Sekhon, R. S.: Objective determination of the noise level in Doppler spectra, J. Appl. Meteor., 13, 808-811, 1974.

Hocking, W. K., Thayaparan, T., and Franke, S. J.: Method for statistical comparison of geophysical data by multiple instruments which have differing accuracies, Adv. Space Res., 27, 10891098, 2001.
Joss, J. and A. Walvogel: Ein Spectrograph für Niederschlagstropfen mit automatischer Auswertung, Pure Appl. Geophys. 68, 240-246, 1967.

Petitdidier, M., Sy, A., and Garrouste, A.: Statistical characteristics of the noise power spectral density in UHF and VHF wind profilers, Radio Sci., 32, (3), 1229-1247, 1997.

Petitdidier, M., Ulbrich, C. W., Laroche, P., Campos, E. F., and Boyer, E.: Tropical Thunderstorm campaign at Arecibo, PR. Proceedings of the ninth workshop on technical and scientific aspects of MST radar and combined with COST-76 final profiler workshop , Toulouse, 13-18 March, editor: Belva Edwards, Scostep secretariat, NOAA, 325 Broadway, Boulder, USA CO80303, 401-404, 2000.

Press, W. H., Flannery, B. P., Teutolsky, S. A., and Vetterling, W. T.: Numerical Recipes: The Art of Scientific Computing, Cambridge University Press, New York, USA., 818, 1986.

Sauvageot, H. and Lacaux, J. P.: The shape of averaged drop size distributions, J. Atmos. Sci., 52, 1070-1083, 1995.

Uijlenhoet, R., Steiner, M., and Smith, J. A.: Influence of disdrometer deadtime correction on self-consistent analytical parametrizations for raindrop size distributions, Proceedings of the European Conference on radar Meteorology, Delft, Netherlands 1822 November, 104-112, 2002.

Ulbrich, C. W. and Lee, L. G.: Rainfall measurement error by WSR$88 \mathrm{D}$ radars due to variations in Z-R law parameters and the radar constant, J. Atmos. Oceanic Tech., 16, 8, 1017-1024, 1999.

Ulbrich, C. W., Petitdidier, M., and Campos, E. F.: Radar properties of tropical rain found from disdrometer data at Arecibo, PR. Proc. of the 29 International Conference on Radar Meteorology, Montreal, Canada, 676-679, 1999.

Williams, C. R., Kruger, A., Gage, K. S., Tokay, A., Cifelli, R., Krajewski, W. F., and Kummerow, C.: Comparison of simultaneous rain drop size distributions estimated from two surface disdrometers and a UHF profiler, Geophys. Res. Lett., 27, 1763-1766, 2000. 